\title{
The Mexican expedition to observe the 8 December 1874 transit of Venus in Japan
}

\author{
Christine Allen \\ Instituto de Astronomía, UNAM, México \\ email: chris@astroscu.unam.mx
}

\begin{abstract}
The voyage of the Mexican commission to observe the transit of Venus on 8 December 1874 in Japan is briefly recounted. The five-man expedition was led by Francisco Díaz Covarrubias. They succeeded in establishing two observing stations near Yokohama, one in Nogue-no-Yama and one on a hill called "The Bluff", and also in determining precise geographical positions for them. Clear skies allowed the observation of the transit at both stations. The results were presented in Paris in 1875, and published on the same year. They were meant as a contribution to be processed along with all other data obtained by different missions. The importance of the expedition for the development of early modern science in Mexico - particularly astronomy - is examined in the broad context of the social and political conditions then prevailing in the country. The relevance of the mission for the establishment of scientific, cultural and even commercial ties between Japan and Mexico is emphasized.
\end{abstract}

\section{Introduction}

The tradition of observing transits of Venus in Mexico seems to go back a long way. Recent research, for instance, has indicated that the Maya were able to observe transits with the naked eye and that they left some records of these observations in Mayapán, one of the last great Maya centers (Ruiz Gallut et al. 2001; Galindo-Trejo \& Allen, these proceedings). In the so-called Fresco Hall, situated in front of the great pyramid in Mayapán, several frescoes are found, reasonably well preserved. The frescoes depict two personages flanking a Sun-circle. Most unusually, the Sun-circles contain within them reclining figures, as if they had been swallowed by the Sun. The figures may be associated with Kukulkan, one of the most important deities in the Maya culture and closely linked to Venus. Radio-carbon dating indicates that the paintings were done between 1200 and 1350 AD. During that interval of time four transits of Venus occurred. The transit of June 1, 1275 was visible at dusk from Mayapán, and it has been proposed as the one actually depicted in the frescoes (Ruiz Gallut et al. 2001; Galindo-Trejo \& Allen, these proceedings). Confirming evidence for this identification can be found in the fact that the orientation of the building is such that the Sun-circles are illuminated grazingly by the Sun on dates centered on the summer solstice and separated by 73 days, one eighth of the synodic period of Venus.

Another historic observation occurred at the time of the 1769 transit (Cassini 1772). The French Academy of Sciences, seeking the best observing conditions, sent an expedition to San José del Cabo, Baja California. The expedition was headed by the Abbé Chappe d'Auteroche. On arrival at San José together with Spanish astronomers Vicente Doz and Salvador Medina, they contacted the Creole astronomers Joaquín Velázquez de León and José Antonio de Alzate, who also intended to observe the transit and had already established an observing station nearby. The weather was fine, and the transit was successfully recorded by all (Moreno 1986b). 
But, most tragically, Chappe, Medina and a French technician died soon afterwards, victims of the yellow fever, an epidemic that caused more than $75 \%$ of the Baja California population to perish. However, the surviving astronomers returned safely with the precious data they had obtained during the transit, which were processed along with those of other expeditions (Díaz Covarrubias 1882). The observations of Velázquez et al. were published side by side with those of Chappe by the Académie Royale des Sciences de Paris. In this way, not only were the results of the expedition salvaged, but also the interest in astronomy in the New Spain, dormant for many years, was re-awakened. Velázquez, for instance, was able to conduct various geodetic studies, Alzate observed and studied the satellites of Jupiter, recorded several lunar occultations, and computed cometary orbits, notably that of the 1788 comet. The stage was set for the transit of the year 1874 .

\section{The 1874 transit}

Curiously, interest in the upcoming transit started with a public lecture by Francisco Díaz Covarrubias at the meeting of the Humboldt Society, Mexico City in April 1874 (Díaz Covarrubias 1882). He explained in great detail the importance of the transit for the accurate determination of the distance to the Sun, and expressed the view that on the occasion of the next transit in early December, as many countries as possible should join forces to better determine this quantity. Those attending the lecture were clearly impressed. However, the situation in Mexico was by no means favorable to scientific endeavors. In fact, the young Republic had lost the war with the US some years previously, and also suffered the French intervention. The economic situation was chaotic, the country divided, civil strife rife...

The reforms of Juarez, continued by Sebastián Lerdo de Tejada, had met with considerable opposition from the church and the big land and mine owners. In the middle of this dramatic situation, several senators and cabinet members somehow managed to convince President Lerdo de Tejada that Mexico should begin to play a role in the international scientific community, and that the coming transit of Venus offered a great opportunity to put Mexico, so to say, on the international scientific map. After being assured of its feasibility, President de Tejada approved the project in early September, asked Díaz Covarrubias to form a commission and head the project, and provided the necessary funding.

In great haste, because time was short and the trip to the places that offered the best possibilities for successfully observing the transit was long and complicated, Díaz Covarrubias formed the Commission, selected and commandeered the necessary equipment and set forth to the Far East, where weather conditions were likely to be best.

The Mexican Commission (see Fig. 1) was composed of the following members:

- Francisco Díaz Covarrubias, Chief astronomer

- Francisco Jiménez, astronomer

- Manuel Fernández Leal, surveyor and analyst

- Agustín Barroso, photographer

- Francisco Bulnes, analyst and chronicler

Díaz Covarrubias found that several government agencies already had equipment suitable for the transit observations. So, from the Ministry of Mines and Development he obtained a zenith telescope, a barometer and a theodolite, from the National School of Engineering a second zenith telescope, and a precise chronometer, and from the Military Academy a refracting telescope and a second chronometer. To complete this equipment, 

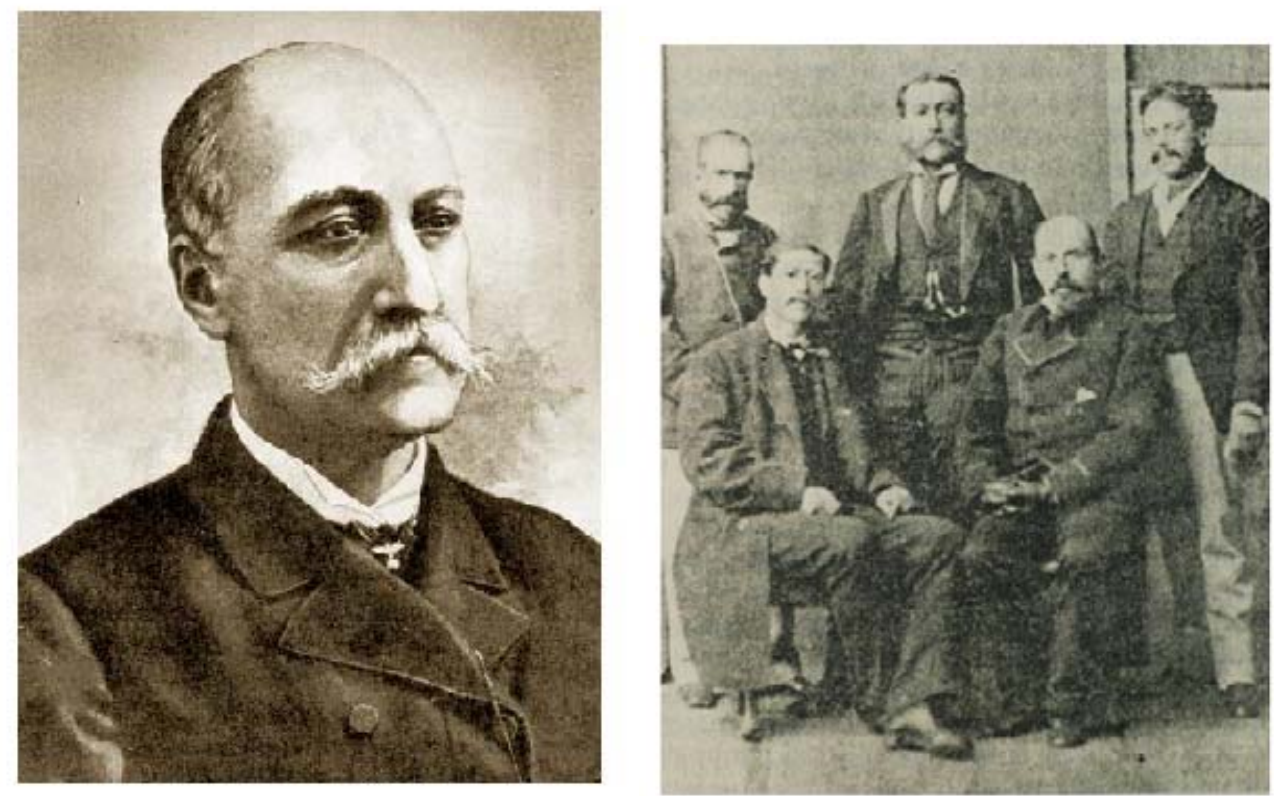

Figure 1. (left) Francisco Díaz Covarrubias. (right) The Mexican Commission. Back row: F. Jiménez, F. Díaz Covarrubias, F. Bulnes. Front row: A. Barroso, M. Fernández Leal.

Díaz Covarrubias took from his private observatory two altazimuth telescopes as well as various small instruments. With these instruments he planned on setting up two observing stations, in order to maximize the probability of fair weather at at least one of them.

\section{The voyage}

All the preparations for the expedition, as well as details of the voyage are described in great detail by Díaz Covarrubias in his book "Viaje de la Comisión Mexicana al Japón, 1874" (Díaz Covarrubias 1876). In this book he gives a detailed account not only of his observations, but also of the trip itself, of the land and people of Japan, of the history, economy and social customs of the Japanese, and even of the religious and sexual mores. It is written in a popular style, strongly reminiscent of Jules Verne.

For the trip to China (where he originally intended to go), he estimated that 55 days would be needed. The trip was by necessity quite indirect, since at that time of the year (just after the rainy season) the roads joining Mexico City with the Pacific coast were impassable, especially for an expedition carrying a considerable load of delicate instruments. The itinerary that Díaz Covarrubias planned is displayed in Table 1.

Table 1. Proposed itinerary of the voyage of the Mexican Commission

\begin{tabular}{lc}
\hline Mexico-New York (via Cuba and Philadelphia) & 12 days \\
New York-San Francisco & 8 \\
San Francisco-Yokohama & 25 \\
Yokohama-Beijing & 10 \\
Total estimated & 55 days
\end{tabular}


Preparations were completed in a short time, and on September 18 the Commission left Mexico City on their way to Veracruz. From Veracruz they sailed to Cuba, then north and upstream to Philadelphia, and onwards to New York. The trip from New York to San Francisco was by rail, on the newly completed Western Line. In San Francisco they stayed a few days, in order to establish some contacts with consular officers and to acquire photographic materials. For the long voyage to the East they boarded the steamer Vasco da Gama. The trip was not easy. They had stormy weather all along. Throughout the voyage, Díaz Covarrubias tried to get information on the places that offered the best weather conditions, and decided finally to set up his observing stations in Japan.

\section{Arrival and setup}

Díaz Covarrubias was already well known in Japan due to several techniques for determining geographical coordinates that had been developed and published by him, and translated into Japanese. As a matter of fact, on his departure, the Minister of Education Fugimaru Tanaka presented him with a copy of his booklet "Nouvelle méthode pour determiner la latitude d'une station au moyen d'observations azimutales" translated into Japanese and just published. The Commission arrived in Yokohama on November 9th. On their arrival, the Commission was received by Terashima Munemory, the Japanese Minister for Foreign Relations, who assured Díaz Covarrubias his full support for the project. Indeed, he offered to pay for the rent of the properties to be selected by the Commission for the erection of the observing stations, an offer that was courteously refused. On learning about the desirability of easy communication with other stations, he ordered a telegraph line to be constructed directly linking the stations with the telegraph office in the city of Yokohama. Also, all communications were to be made free of charges.

As it turned out, there was just time to obtain the necessary permissions, to determine the best locations and to start construction of two observing stations at "Nogue-NoYama" and "The Bluff" (see Fig. 2):

Both stations were built by a Chinese worker, Mow Cheong, according to specifications by Díaz Covarrubias. By the end of November they were ready.

At that time, there were no diplomatic relations between Mexico and Japan, so that the formal introductions and the initial negotiations had to be conducted through the US Consul J.A. Bingham. Collaboration was always in the best terms, though. Díaz Covarrubias was even granted permission to hoist the Mexican flag at both stations, a most unusual concession in the absence of diplomatic relations.

Díaz Covarrubias established contact with the French and American Commissions in Nagasaki, under Jenssen and Davidson, respectively. At the request of the Japanese Government Díaz Covarrubias took on as trainee-assistants several gentlemen (from the Japanese Navy and the Education Ministry).

\section{Preliminary observations}

Díaz Covarrubias decided early on to set up two stations, but since they were by necessity close together (separated by just over $2 \mathrm{~km}$ ) it was clear that his transit data would have to be processed together with those obtained by other missions. The method they chose to observe was the visual timing of the four contacts (to be used along with data from other missions for determining the solar parallax by Halley's method), but they also attempted to observe the position of Venus on the Sun's disk (to employ Delisle's method). For the latter procedure, it was imperative to know precisely the geographic 

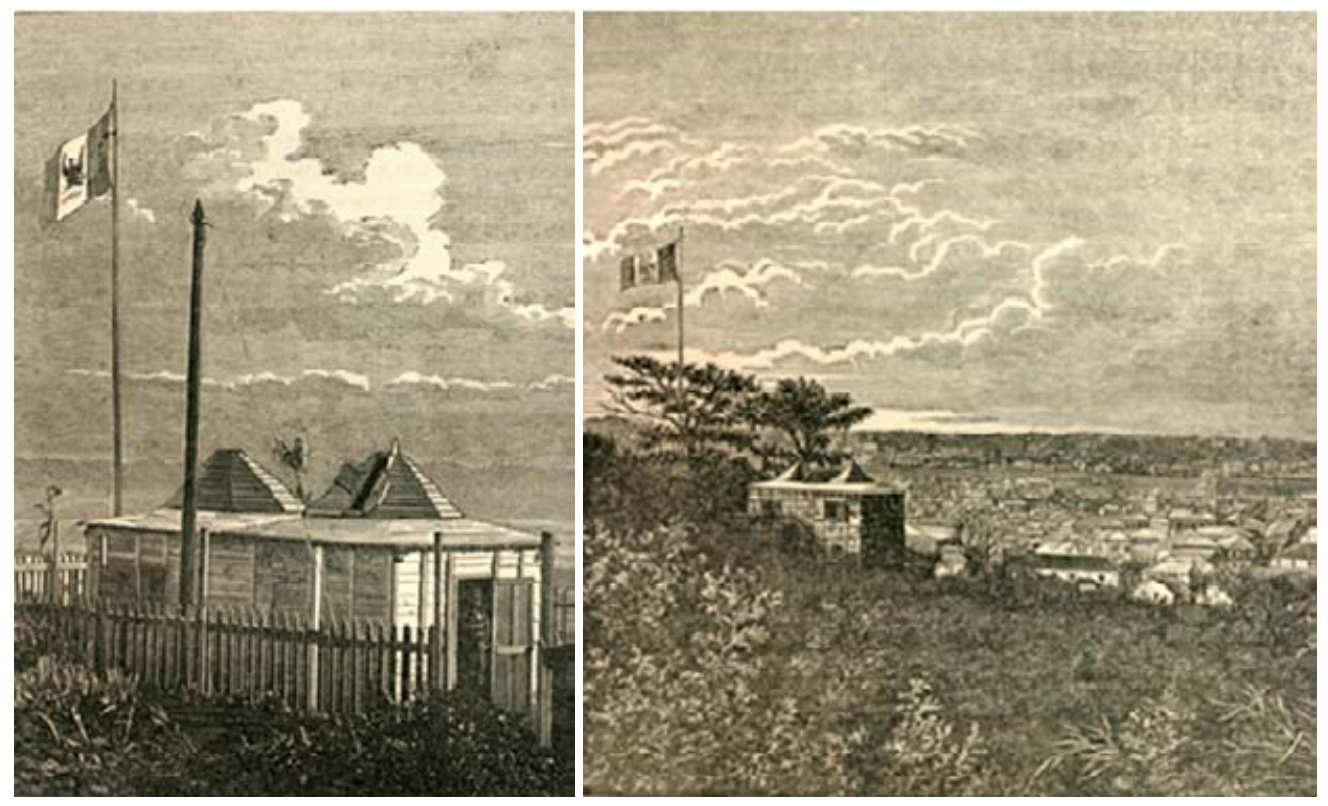

Figure 2. (left) The observing station at Nogue-No-Yama. (right) The observing station at "The Bluff".

coordinates of the stations, as well as to have accurately calibrated chronometers. They proceeded therefore to the determination of times, latitudes and longitudes (both absolute and differential). For the times, they observed meridian passages of a number of stars, for the latitudes they used four different methods (among them the so-called "Mexican method", developed by Díaz Covarrubias), and for the absolute longitudes they observed lunar culminations, occultations of stars and culminations of about 55 stars. They also exchanged a number of telegraph signals with Tisserand, and Davidson, of the French and American stations. The final results of these determinations, as given in the original publication, (Díaz Covarrubias 1875) are displayed in Fig. 3. The "Legación de Rusia" point was included at the request of O. W. Struve who was in Yokohama to observe the transit.

\section{The December 8 transit of Venus}

The morning of December 8, the transit day, appeared bright and clear in Yokohama, a great relief after several cloudy days. The transit was successfully recorded both at Nogue-No-Yama station, by Díaz Covarrubias himself, and at the Bluff, by Jiménez. The telescopes were fitted with projection screens, which enabled several people to observe the event. As a matter of fact, Díaz Covarrubias allowed the public to watch the transit, gave extensive explanations and answered many questions, only requesting absolute silence when the four times of contact were approaching. The Minister of Education was among those present at Nogue-No-Yama.

Unfortunately, Díaz Covarrubias had to share the disappointment of most of the missions, because the dreaded black drop effect was again present and spoiled the expected accuracy of the observations. His two stations were separated by close to 5 seconds in longitude. Since the transit occurred practically at the same time at both of them, in the absence of errors his measurements should have differed by exactly 5 seconds from 


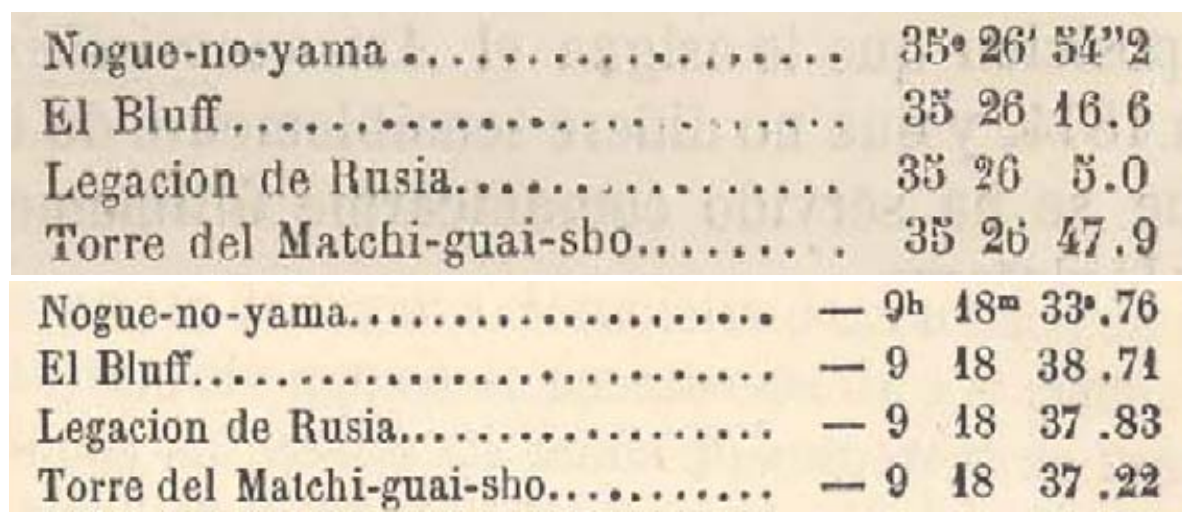

Figure 3. Latitude (top) and longitude (bottom) determinations for the stations at Nogue-No-Yama and The Bluff, as well as for other significant points. The tables are taken from the original publication (Díaz Covarrubias 1875).

those of Jiménez. In fact, they differed by various amounts, up to 20 seconds. The measurements, as they appear in the original publication, are displayed in Fig. 4.

Even before the full reduction of his data, Díaz Covarrubias (1875) expressed doubts about the expected accuracy in the following words:

"In spite of the great number of observations, we doubt very much that the 1874

transit will be able to furnish the correct second digit for the solar parallax."

However, he also held the optimistic view that by combining many observations from a large number of stations the errors would, to a certain extent, cancel out, and ultimately provide an improved value for the solar parallax.

The photographer of the Commission, A. Barroso, was able to secure some 14 photos of the transit. They were obtained with a very primitive camera, and were intended merely as a test for the application of the then very new photographic techniques to astronomical observations (see Fig. 5).

After the transit was over, Díaz Covarrubias proceeded to exchange further telegraphic signals with the French astronomers. During the trip back, via China and Europe, Díaz Covarrubias worked with Tisserand on the reductions of these determinations, and both were able to further refine their time and longitude measurements.

The results of the observations at both stations were reduced and prepared for publication by Díaz Covarrubias on his trip back to Mexico. Work was advanced to the point that, when Díaz Covarrubias arrived in Paris, the results were ready for publication (see Fig. 6). The Mexican Commission was the first to publish their results. As already mentioned, they were intended to be processed along with the results of other observers to establish the "best value" of the astronomical unit. To deal with a great number of results from different missions, G.B. Airy recommended that all data be processed in a prescribed way, so as to ensure uniformity among different groups, and only then submitted to him for final evaluation. The Mexican data were reprocessed according to Airy's recommendations, and duly submitted. They were received by the Greenwich Observatory on May 26, 1876.

\section{Repercussions of the voyage - scientific and otherwise}

President de Tejada was subjected to sharp criticism for funding such a "useless" project, at a time when the Nation was impoverished and had many other pressing needs. 
Primer contacto exterior.............

Primer contacto in terior

1874. -Diciembre 8 á $23 \mathrm{~h} 4$ 至 79.0

Ruptura del ligamento..............

Formacion del ligamento.............

Segundo contacto interior.............

Segundo contacto exterior.

Fases.

Primer contacto exterior..............

Primer contacto interior..............

Ruptura del ligamento,..............

Formacion del ligamento..............

Segundo contacto interior.............

Segundo contacto exterior.............

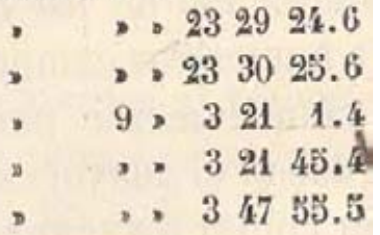

Horas medias del Bluff.

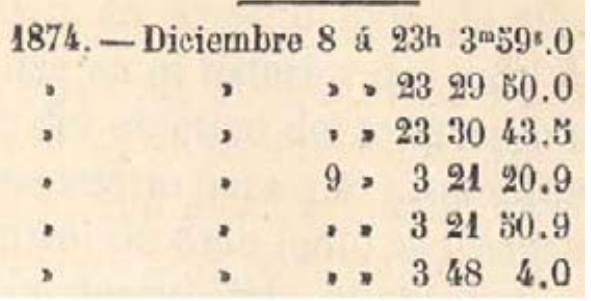

Figure 4. Transit measurements obtained at Nogue-No-Yama by Díaz Covarrubias and at The Bluff by Jiménez. The table is taken from the original publication (Díaz Covarrubias 1875).

The trip of the Commission was perceived by some as a world tour with all expenses paid for some privileged individuals. Perhaps the haste of Díaz Covarrubias to publish his results was intended to silence such critics (and to prevent being accused of copying the results). But the success of the mission soon turned public opinion around, and Díaz Covarrubias was welcomed back enthusiastically (Moreno 1986b). Even the most severe critics soon afterwards supported the creation of an observatory for Mexico. In this manner, the voyage of the Commission paved the way to the foundation of the National Astronomical Observatory, created by presidential decree in 1876 and officially dedicated on May 5, 1878. The National Astronomical Observatory is the direct precursor of our present Institute of Astronomy.

A few years later, in 1887, astronomers from the National Observatory attended the Astrophotographic Congress in Paris, and were invited to participate in the Carte du Ciel project, one of the large international astronomical projects at the time. The next transit of Venus occurred in 1882 and was observable from Mexico. In fact, a French Commission, under Bouquet de la Grye, travelled to Puebla, and successfully observed the transit. The National Observatory, then at Chapultepec Castle, Mexico City, was already in operation, and had instruments suitable for observing the transit, among them a photoheliograph and a meridian telescope. Unfortunately, the skies were cloudy in Mexico City, thus preventing the observation of the transit there. But Mexican astronomers re-established contacts with their French colleagues, and these contacts ultimately lead to the invitation to the Carte du Ciel project (Moreno 1986a).

Going back to the 1874 transit, Díaz Covarrubias returned to Mexico most favorably impressed by the people and government of Japan. A firm basis for further collaborations with them was assured, leading in time to full diplomatic relations. Several circumstances were to facilitate the establishment of relations between Mexico and Japan. Let us recall that Mexico achieved independence from Spain in the early 19th century. After many conflicts and revolts, Mexico enjoyed a peaceful period during the presidency of Porfirio Díaz (1876-1880, 1884-1911), which led to relative prosperity, economic growth, and 


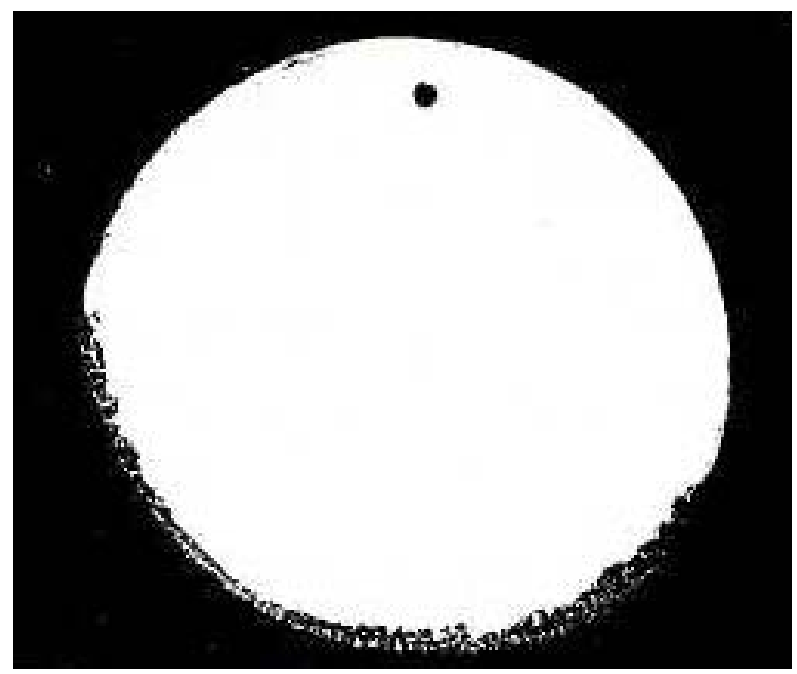

Figure 5. Photo of the transit obtained by Barroso.

international exchange. Due to its geographical location, its natural resources and a deliberate effort by the government to seek wider internationalism, Mexico offered advantages to Japan in its opening to the West during the Meiji Restoration (Alvarez 1996). After many centuries of being a closed society, Japan was seeking international contacts. Díaz Covarrubias realized that it would be of advantage to Mexico to look for a treaty for trading with Japan, and he was an active promoter of the establishment of full diplomatic relations. Díaz Covarrubias' book was helpful in providing much detailed information about Japan. The chronicler of the Commission, Francisco Bulnes, also published a book that enjoyed some success (Bulnes 1875).

In 1888 Ministers Matías Romero (Mexico) and Munemitu Mutsu (Japan) signed the Treaty of Friendship, Commerce and Navigation in Washington, D.C. This treaty was not only the first one signed by Japan with a Latin American country, but also the first written in completely equitable terms. It was also the first treaty signed by Mexico with an Asian nation. As a result of these negotiations, Mexico sent its first diplomatic mission with José Martín Rascón as chargé d'affaires, and Japan sent Tatemu Gozo as Consul in Mexico (Ota-Mishima 1982). Ironically, both the treaty and the transit are better remembered in Japan than in Mexico. So, for example, the municipal authorities in Yokohama rescued the masonry slab upon which one of Díaz Covarrubias' telescopes was erected and had it engraved as a plaque in remembrance of the Mexican expedition. It is now located in a Yokohama public park (see Fig. 7). Soon afterwards, the trade treaty led to the establishment of full diplomatic relations between Mexico and Japan.

In those times, Mexico was sparsely populated. The Mexican government saw immigration as a way to encourage growth. Japan already then had serious demographic problems, and therefore promoted the establishment of Japanese settlements in other countries. Díaz Covarrubias, having been very favorably impressed by the industriousness, the discipline, and the eagerness to learn shown by the Japanese people, vigorously promoted Japanese immigration to Mexico. In 1897 the first group of 36 Japanese immigrants arrived to Escuintla, Chiapas. Manuel Fernández Leal, a member of the original Commission, and later Minister of Mines and Industry, was directly responsible for this program. Later, other groups arrived to be employed at mines in the North or plantations in Yucatán. By 1941 a total of about 14500 Japanese immigrants had settled in Mexico. 


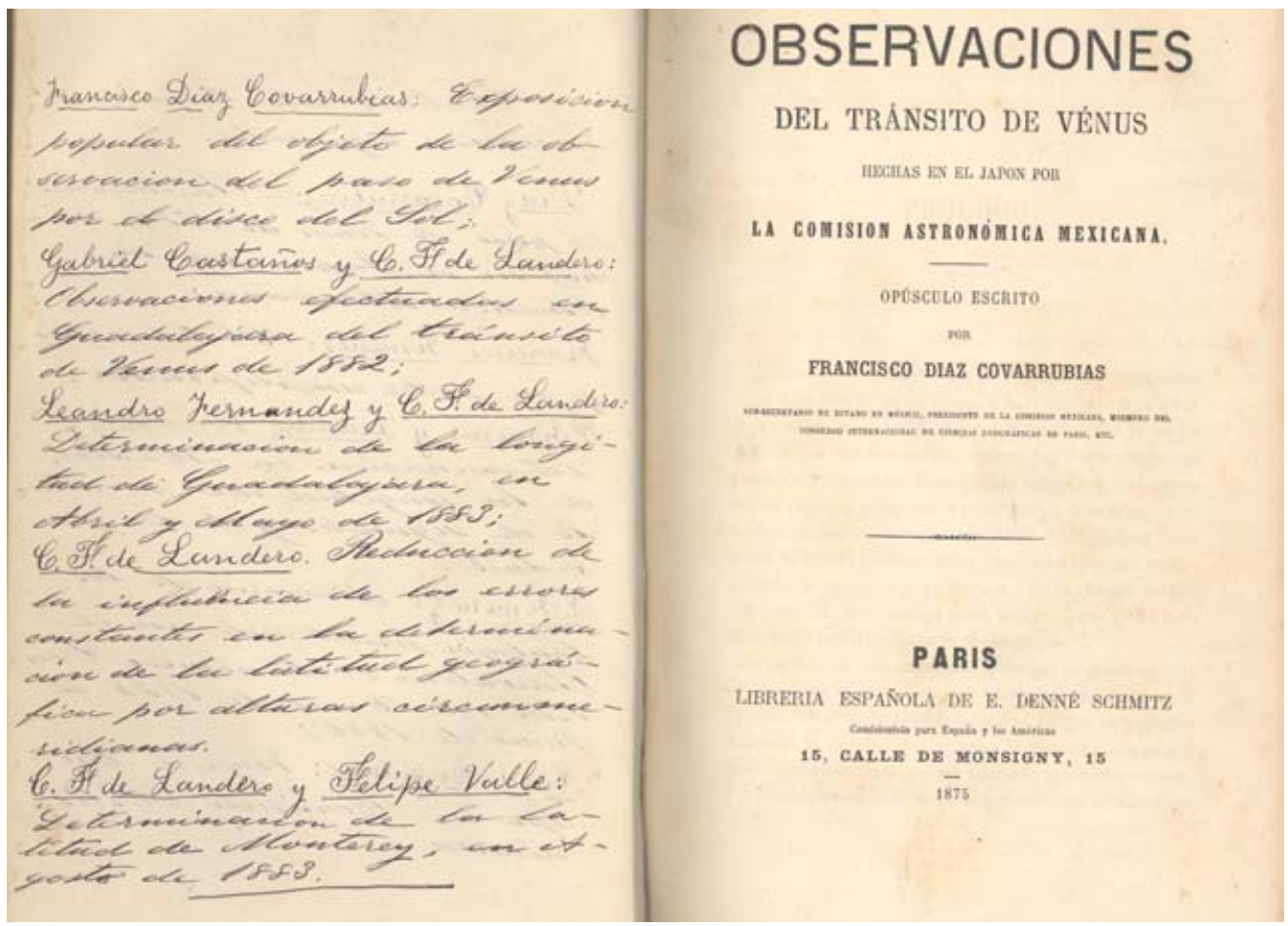

Figure 6. Original publication by Díaz Covarrubias 1875 .

As Díaz Covarrubias had foreseen, they adapted very well, they prospered, and later generations were largely assimilated. In this way, the voyage of the Mexican Commission to observe the transit of Venus was important also for many non-astronomical reasons.

I will finish by quoting the words of farewell to the Commission of the Japanese Minister for Education (Díaz Covarrubias 1876):

"Your presence in this country has been as pleasant as it has been useful, because you have given our youth instruction... Instead of bringing arms and destruction, you have brought to us the brotherhood of the sciences..."

And last, but not least, the transits won considerable public support for astronomy. Perhaps harking back to the old pre-Hispanic traditions that considered Venus an important deity, the transits caught the public's imagination. Just to mention an example: a pub in Mexico City opened with the very sober name "El tránsito de Venus por el disco del Sol' (alas, it no longer exists!). The success of the Mexican expedition became a source of national pride and contributed to provide a sense of cultural identity in Mexico.

\section{Acknowledgements}

I am indebted to Mr. I. Venteño, of the Autonomous University of Ciudad Juárez for providing a copy of the original Díaz Covarrubias (1875) publication. My sincere thanks to J. Galindo-Trejo and A. Poveda for useful discussions, to J. C. Yustis for obtaining the photographs and to P. Ronquillo for her help with the latex macros. 

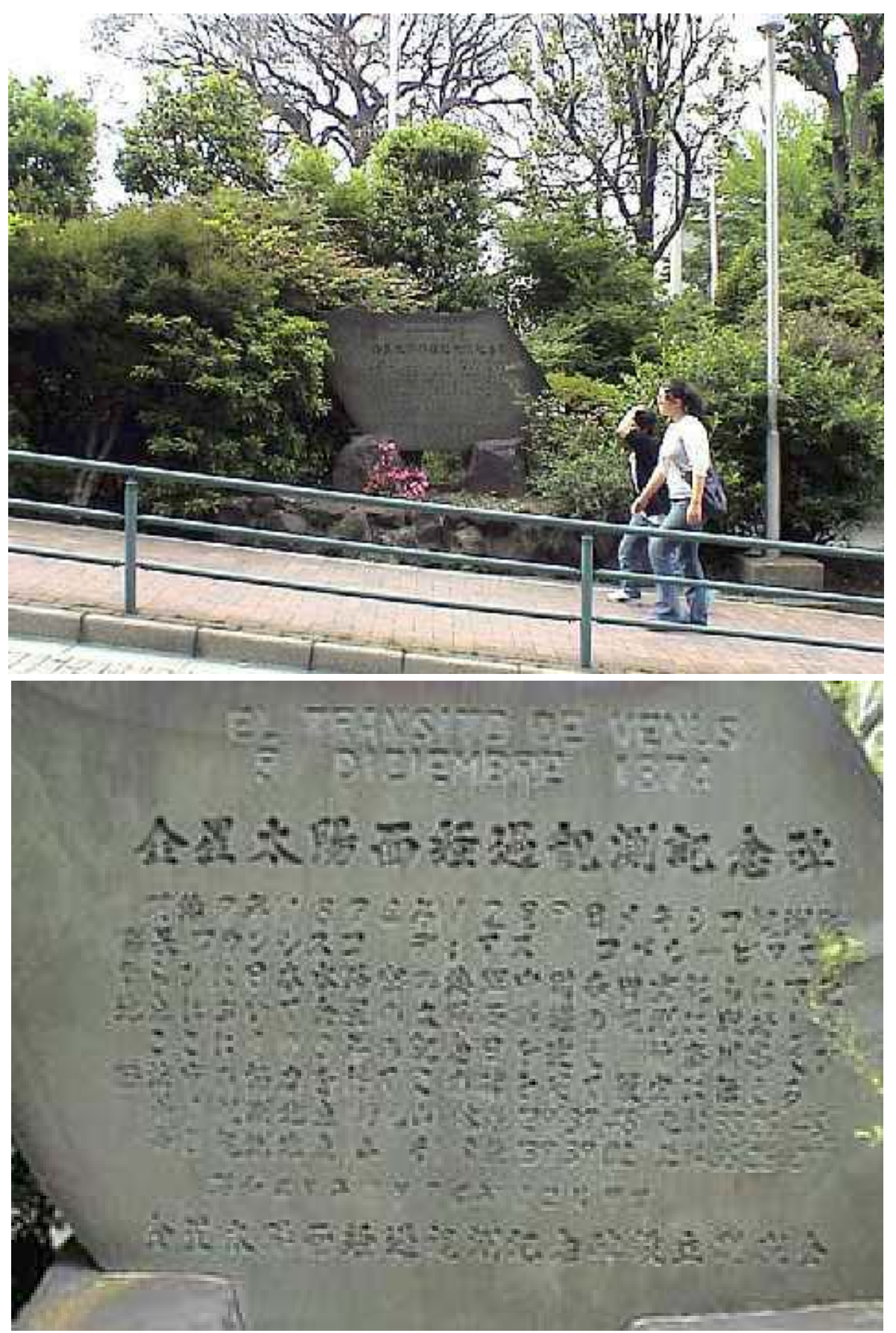

Figure 7. Masonry slab upon which one of Díaz Covarrubias' telescopes stood, engraved as a plaque remembering the Mexican expedition. This plaque is displayed in a Yokohama public park. 


\section{References}

Alvarez J. R. 1996 Enciclopedia de México. 4467.

Bulnes F. 1875 "Sobre el Hemisferio Norte once mil leguas. Impresiones de viaje a Cuba, los Estados Unidos, el Japon, China, Cochinchina, Egipto y Europa". Imprenta de la Revista Universal.

Cassini M. 1772 Voyage en California pour l'Observation du Passage de Venus sur le Disque du Soleil, le 3 Juin 1769. Paris, Antoine Jombert.

Díaz Covarrubias F. 1875 "Observaciones del tránsito de Venus hechas en Japón por la Comisión Astronómica Mexicana". Paris: Libreria Española de E. Denne Schmitz.

Díaz Covarrubias F. 1876 "Viaje de la Comisión Astronómica Mexicana al Japón para observar el tránsito de Venus por el disco del sol el 8 de Diciembre de 1874”. México: Imprenta Poliglota de C. Ramiro y Ponce de León.

Díaz Covarrubias F. 1882 "Exposición Popular del Objeto y la Utilidad de la Observación del Paso de Venus por el Disco del Sol". Guadalajara, México: Tipográfica de M. Perex Lete.

Moreno M. A. 1986a "Historia de la Astronomía en México" México, Fondo de Cultura Económica.

Moreno M. A. 1986b "Odisea 1874, o el Primer Viaje Internacional de Científicos Mexicanos" México, Fondo de Cultura Económica.

Ota-Mishima M. E. 1982 "Siete Migraciones Japonesas en México". México, El Colegio de México.

Ruiz-Gallut M. E., Galindo-Trejo J., \& Flores-Gutiérrez D. 2001 "La Pintura Mural Prehispánica en México". Ed. B. de la Fuente, México, UNAM, p.265.

\section{Discussion}

STEVE Dick: Do you know any details about how that result was produced so fast from the 1874 transit? It was reduced at Greenwich - is that what you said?

Christine Allen: The preliminary data reduction was done along the way on the voyage back. There were data only for two stations and, of course, they couldn't give a value for the parallax - for the astronomical unit - but they did take into account things had to be taken into account - refraction, for example.

STEVE Dick: Why could they not give the value of the astronomical unit?

Christine Allen: Because the two stations were very close together. They couldn't possibly.

STEve Dick: Was that data combined with others eventually?

Christine Allen: They were meant to be combined with other data. I don't know if that actually happened; I haven't been able to find out. I do know that the data did arrive at Greenwich observatory and that they were pre-processed by Covarrubias according to Airy's recommendations, but that's all I can say.

WAyne Orchiston: A fascinating paper congratulations, I really enjoyed it.

Christine Allen: Thank you.

WAYNE ORCHISTON: What excited me particularly were the very early murals you presented there - these paintings dating between 1200 and 1230. I'm aware of the fact that Richard Stevenson has carried out a detailed analysis of all the early Asian records to try and determine whether there's any documentation of observations of transits in the Far East (as we call it) from here [UK] and by Chinese, Japanese, Koreans, and so 
on - knowing the dates of different transits - and he could find no documentation whatsoever, and so we all safely say the first transit was observed in 1639 from very near here [Much Hoole]. If, in fact, these claims that are made are correct, we are actually pushing back the boundaries for the earliest dates. So my question is this: when are these people who carried out this analysis going to publish in English so that the rest of the astronomical community can share this information, and also so people like Richard Stevenson can carry out an analysis and basically support them in this wonderful finding?

Christine Allen: The paper has actually been published in Spanish - I can give you the reference. I can give you a Xerox copy! I have it with me.

Wayne Orchiston: ... but in English?

Christine Allen: That's something I cannot say. There are three authors. One of them is a colleague of mine at the Institute, and the others are archaeologists and, I will try to convince them to present their work to the astronomical community.

[The following paper is a completely new discussion of this work that was researched, written and included in these proceedings as a result of this discussion.]

DAvid SEllers: You said that the observation was by projection; did Covarrubias just time the internal contacts or did he take measurements during the progress, and if so how: using the projection method? Did they make accurate measurements of the position of Venus on the solar disc? Do you know?

Christine Allen: As far as I know, they didn't try to measure the position across the solar disc - just the times of the contacts.

RIChard Strom: Just a follow-up to Wayne's comment: One might worry whether they didn't actually see sun spots; I wonder about what is known about Mayan observations that might have been related to sun spots. Do you know anything about that?

Christine Allen: Actually, one of the sun circles is covered with spots. This suggests that the Maya were familiar with sunspots and did not confuse them with Venus. Then, of course, you have this alignment of the building with a fraction of the synodic period of Venus, which again suggests an association with Venus itself - suggests, but cannot prove.

MARY BRÜCK: Thank you, Christine, for a charming story which has a happy ending; in fact, several happy endings. 


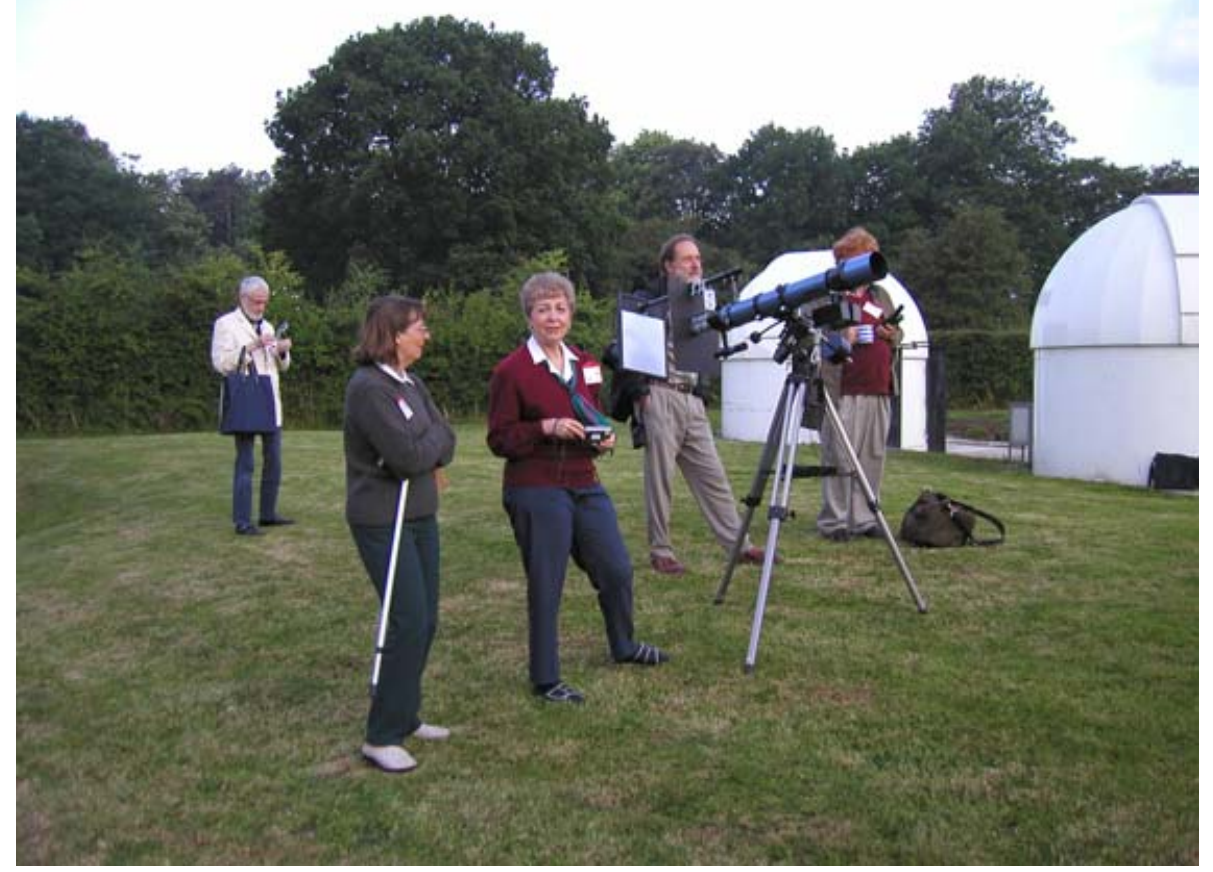

Jeannie Allen and Christine Allen during the Transit

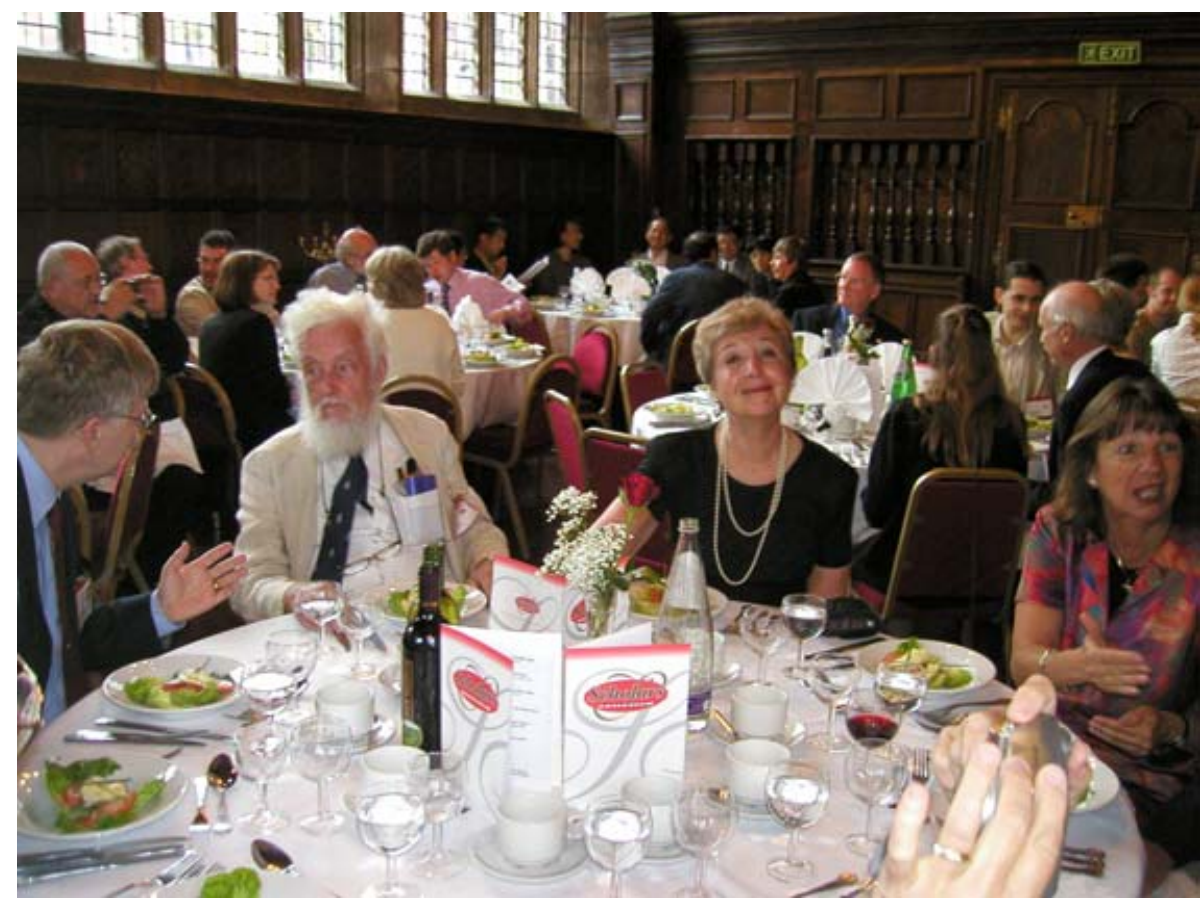

Steve Dick, Jim Message, Christine Allen and Jeannie Allen at Hoghton Tower 